\title{
Systematic review and meta-analysis of target terapies for the treatment of metastatic renal cancer
}

\author{
Marcela Durán, Wagner Matheus, Ubirajara Ferreira, Otávio Clark \\ Faculty of Medical Sciences, Department of Oncological Urology (MD, WM, UF), Universidade Estadual \\ de Campinas and Evidências Credibilidade Cientifica (OC), Campinas, SP, Brazil
}

\section{ABSTRACT}

Objectives: At present there are several drugs for the treatment of advanced renal cell carcinoma (ARCC). The main objective of this work was to perform a systematic review (SR) and meta-analysis (MA) of clinical randomized studies that compared target cell therapies (TCT).

Materials and Methods: SR identified clinical randomized trials that compared TCT versus interferon-alpha in the treatment of patients with ARCC. In order to analyze efficiency, it was evaluated free-survival progression (FSP), total survival (TS) and response rate (RR). Results: In relation to first line treatment, seven studies of TCT were identified using sunitinib, sorafenib, bevacizumab and temsirolimus; and two studies with sorafenib and everolimus for second line treatment. Relative risk (RRi) of MA for FSP of first line therapies was: $0.83, \mathrm{CI}=0.78-0.87, \mathrm{I} 2=94 \%$ and $\mathrm{p}<0.00001$. Best results of RR of specific FSP among studies were: 0.38 , sunitinib, $\mathrm{CI}=0.25-0.58$, bevacizumab, $0.62, \mathrm{CI}=0.47-0.83$; and temsirolimus, $0.78, \mathrm{CI}=0.70-0.87$. MA didn't show any benefit regarding TS of first line treatment of all analyzed drugs. As for RR significant results were: sunitinib, 3.83 $\mathrm{CI}=2.86-5.12$; bevacizumab, $2.52 \mathrm{CI}=1.78-3.57$ and bevacizumab, $1.97 \mathrm{CI}=1.43-2.71$. Conclusions: For first line treatment, sunitinib was the most effective TCT in relation to FPS; there was no alteration of TS and RR was small but significant for sunitinib and bevacizumab. Available studies could not conclude any results for second line treatments.

\section{ARTICLE INFO}

\section{Key words:}

Kidney Neoplasms; Tissue

Therapy; Meta-Analysis as

Topic; Review [Publication

Type]

Int Braz J Urol. 2013; 39: 768-78

Submitted for publication:

October 19, 2012

Accepted after revision:

September 09, 2013

\section{INTRODUCTION}

The best treatment for renal tumor is surgery, especially when the tumor is located in the kidney with no lymph node involvement or metastasis. In advanced renal cell carcinoma (ARCC), being the tumor incurable, most available treatments are palliative and the patients usually die. In those cases, the objective is to increase total survival (TS), free survival progression (FSP), response rate (RR) and quality of life (QF) of patients.

Before target cell therapies (TCT) became available, interleucin-2 (IL2) and interferon-alpha
(IFN- $\alpha$ ) were the main used therapies for this disease, with low response, from 5\% to $20 \%$ (1-4). At present, TCT include sorafenib, sunitinib, bevacizumab, temsirolimus and everolimus.

Sorafenib and sunitinib are oral inhibitors of tirosine-kinases. Sorafenib inhibits endothelial growth receptors (VEGF) and platelet-derived growth factors (PDGF). Sunitinib inhibits VEGF 1, 2 and 3 with antitumor and anticoagulant effects.

Bevacizumab is a recombinant humanized monoclonal antibody that combines to a VEGF and inhibits its biological activity. It is used intravenously. 
Temsirolimus is an inhibitor of rapamicin-kinase (mTOR) with antiangiogenic effect, as well as everolimus. Everolimus is used orally.

\section{MATERIAL AND METHODS}

Systematic review (SR) was made by search of clinical randomized trials (CRT) that used TCT to treat ARCC compared to IFN- $\alpha$ as first and second lines of treatment.

The search was made at the databases EMBASE, LILACS, MEDLINE, The Cochrane Controlled Trials Register, Cochrane Database of Systematic Reviews and Cochrane Clinical Trials.

Other sources included American Society of Clinical Oncology, European Society of Medical Oncology, Brazilian Society of Clinical Oncology, Cancer Brazilian Society, American Society of Urology and Brazilian Urological Society. search:

The following key words were used for the

("Kidney Neoplasms" [Mesh] OR kidney cancer OR renal carcinoma) AND ("Randomized Controlled Trial" [Publication Type] OR random* OR single blind OR double blind "First Line Therapy and Renal Cancer") AND ("First Line Therapy and Renal Cancer and Randomized Controlled Trials" [Mesh]) AND ("Second Line Therapy and Renal Cancer and Randomized") [MESH].

The selected studies were realized from January 2000 to December 2011, in English, Spanish or Portuguese.

The obtained summaries were evaluated by two independent reviewers and those who fulfilled the select criteria were pre-selected. When both reviewers disagreed, the article(s) was (re) reviewed by a third reviewer.

The inclusion criteria were: multicentric randomized double-blind studies that compared TCT with IFN- $\alpha$. All studies that did not meet those criteria were excluded and those in duplicity were considered only one time.

The studies were identified by the reviewers by the first author's name and year of publishing. All data were directly obtained from the studies or calculated based on the available information: epidemiological data, methods and results, including FSP, TS and RR. Bias methodological aspects
(5) were also analyzed, including randomization methods, double-blind aspects, intention of treatment, loss of patients, sample size, multicentricity and study sponsors.

Statistic analysis was based on the null hypothesis that TCT does not change the results of the treatment. It was used the software Review Manager 5.1 (Cochrane Collaboration Software) (6). In the hypothesis test the level of significance was $\alpha=0.05$ for the rejection of the null hypothesis, in a two-tailed test.

\section{META-ANALYSIS}

Meta-analysis of the quantitative variables related to TS, FSP and RR were done by Relative Risk (RRi) (6).

\section{HETEROGENEITY ANALYSIS}

In the present study we used the heterogeneity index $\mathrm{I}^{2}$ based on the chi-square test calculus (7). When it was observed heterogeneity at meta-analysis with $\mathrm{I}^{2}>70 \%$ the reason was researched (5) using new analysis excluding discrepant studies in order to obtain new heterogeneity indexes (5).

\section{RESULTS}

\section{Systematic Review}

After the search using the selected key words and databases, 148.805 studies were initially selected, related to renal cancer. In order to select those randomized studies that used TCT, new key words were applied and it was obtained 375 references. Among these, after analysis of the summary, 33 were selected to detailed analysis of the complete article and 21 were excluded (Figure-1).

Thirteen studies were included for systematic revision analysis, divided by: first line treatment: Cella et al., 2008 (8); Escudier et al., 2007 (9), 2009 (10); 2010 (11); Hudes et al., 2007 (12); Motzer et al., 2007 (13), 2009 (14); Rini et al., 2008 (15); Rini et al., 2010 (16); Yang et al., 2010 (17) and second line treatment: Escudier et al., 2007 (18); Motzer et al., 2008 (19) and Bukowski et al., 2007 (20). 
Figure 1 - Search result: systematic review.

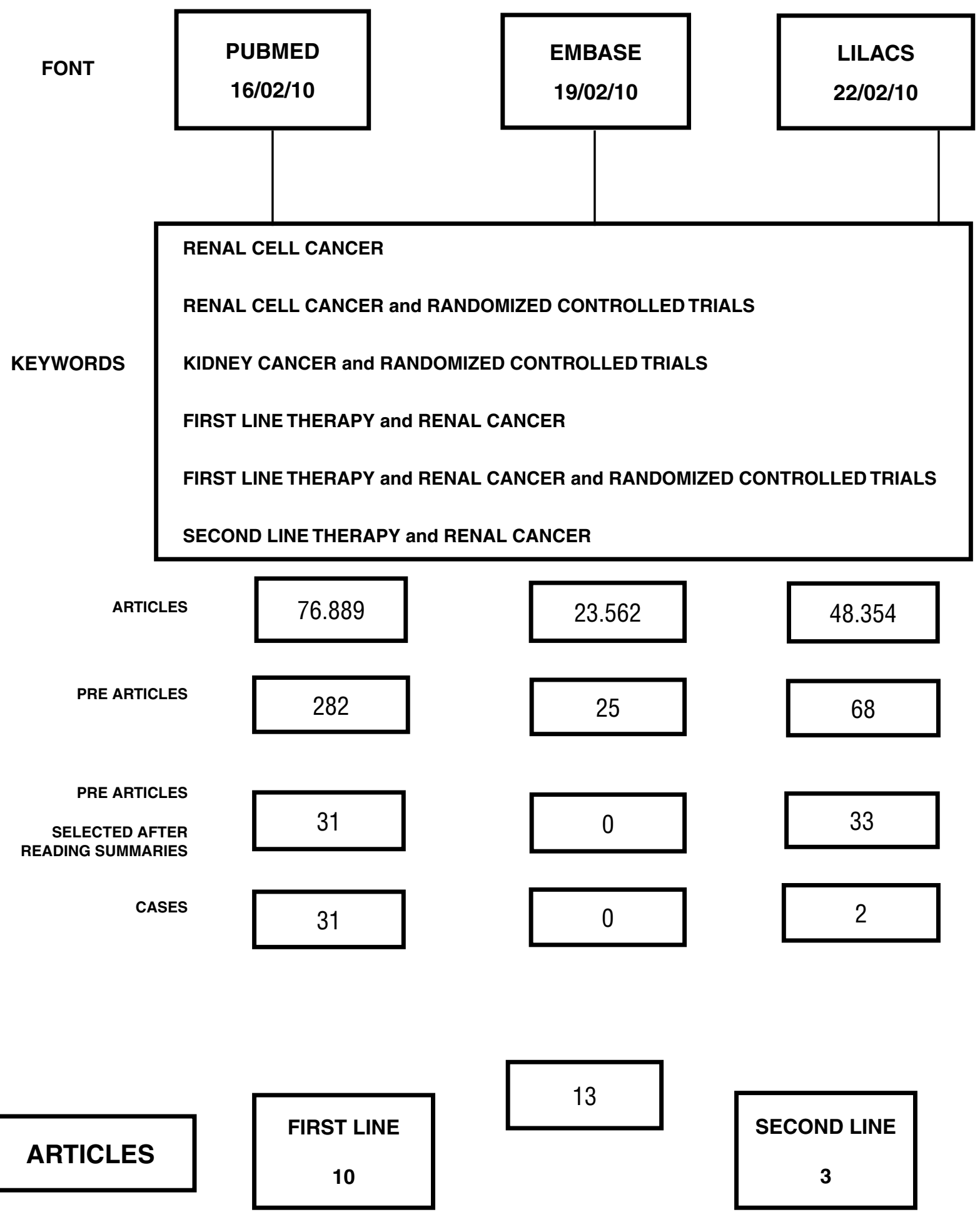


Most patients of those studies, although with different selection criteria, had the following characteristics: age greater than 18 years old, metastatic renal clear-cells tumor, no previous systemic therapy, good medullar response, good hepatic and renal function, good condition, ECOG (0-1) or Karnofsky $\geq 60$ or $70 \%$. Patients with metastasis, radicular compression, uncontrolled systemic hypertension, pregnancy and uncontrolled thyroid diseases were not included.

\section{Quality of the Studies}

The evaluated studies were heterogeneous and most were sponsored by the laboratories manufacturers. Most were randomized studies, double-blind and multicentric. The studies were classified as originals or complementary: the originals are initial studies of analysis of first publication (interim analysis) and the complementary when final analysis was described in a posterior publication (Table-1).

\section{META-ANALYSIS}

Not all selected studies were evaluated at meta-analysis due to the selected end points. Only seven articles of first line treatment and two of second line were evaluated.

\section{Free Survival Progression (FSP)}

Regarding FSP, meta-analysis used 1375 treated patients with target cell therapies (first line treatment) versus 1353 treated patients with interferon-alpha (control group). Among these patients, 628 progressed in group TCT and 746 in control group (Figure-2).

Meta-analysis showed RRi of $0.83, \mathrm{IC}=0.78$ $0.87, I^{2}=94 \%$ and $\mathrm{p}<0.00001$, and the best parameters were observed of the sunitinib study with RRi of 0.38, CI = 0.25-0.58 (Motzer et al., 2007 (13)), followed by the bevacizumab study with RRi of 0.62 , $\mathrm{CI}=0.47-0.83$ (Escudier et al., 2007 (9)) and temsirolimus, RRi of $0.78 \mathrm{CI}=0.70-0.87$ (Hudes et al., 2007 (12)). Worse results were from the study with bevacizumab, with RRi of 0.97, CI = 0.92-1.02 (Rini et al., 2010 (16)) and the study of sorafenib, with RRi of $0.96 \mathrm{CI}=0.83-1.11$ (Escudier et al., 2009(10)).

\section{Total Survival}

Four studies evaluated TS. Rini 2010 (16) did not inform how many patients survived or died in each arm, and the study was excluded at final

Table 1 - Metodological characteristics of the included studies.

\begin{tabular}{lccccccc}
\hline Author & Year & N & randomized & Multicentric & Double blind & Line of treatment & Study analysis \\
\hline Escudier et al. (18) & 2007 & 903 & NC & Y & Y & 2 nd & 0 \\
Escudier et al. (9) & 2007 & 649 & A & Y & Y & 1 st & 0 \\
Escudier et al. (11) & 2010 & 649 & A & Y & Y & 1 st & C \\
Motzer et al. (19) & 2008 & 410 & A & Y & Y & $2 n d$ & 0 \\
Hudes et al. (12) & 2007 & 626 & A & Y & NC & 1 st & 0 \\
Yang et al. (17) & 2010 & 626 & A & Y & Y & 1 st & C \\
Escudier et al. (10) & 2009 & 189 & A & Y & NC & 1 st & 0 \\
Rini et al. (15) & 2008 & 732 & A & Y & N & 1 st & 0 \\
Rini et al. (16) & 2010 & 732 & A & Y & N & 1 1st & C \\
Motzer et al. (13) & 2007 & 750 & A & Y & N & 1 st & 0 \\
Motzer et al. (14) & 2009 & 750 & A & Y & N & $1 s t$ & C \\
Cella et al. (8) & 2008 & 750 & A & Y & N & $1 s t$ & $C$ \\
\hline
\end{tabular}

A - Acceptable; Y - Yes $\mathbf{N}$ - No; $\mathbf{O}$ - Original study; C - Complementar study; NC - not clear 
Figure 2 - Meta-analysis of free survival progression.

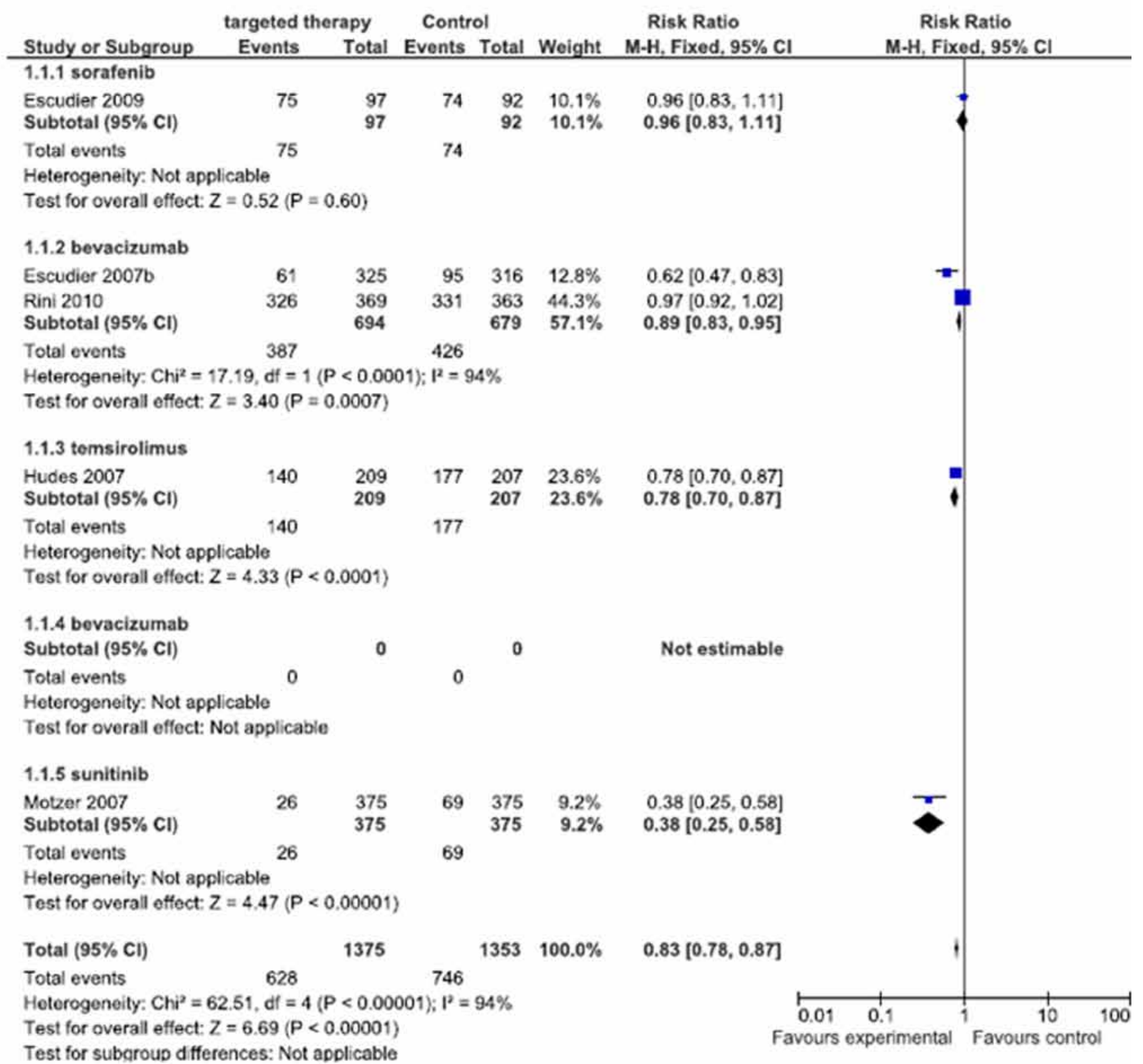

analysis. Among the considered studies, it was evaluated TS of 1007 patients treated with TCT and 990 with interferon-alpha, and 422 and 443 died respectively (Figure-3).

Meta-analysis RRi of TS was $0.94, \mathrm{CI}=$ $0.86-1.02, \mathrm{I}^{2}$ of $0 \%$ and $\mathrm{p}=0.14$. The values of RRi of each study were: sorafenib: RRi $0.63 \mathrm{CI}=$ 0.23-1.71 (Escudier et al., 2009 (10)), bevacizumab: RRi $0.95 \mathrm{CI}=0.86-1.06$ (Escudier et al., 2007 (9)), sunitinib: RRi $0.95 \mathrm{CI}=0.83-1.09$ (Motzer et al., 2007 (13)) and temsirolimus: RRi $0.59 \mathrm{CI}=0.22-$ 1.61 (Hudes et al., 2007 (12)).

\section{Respost Rate}

RR was analyzed in 1375 patients treated with TCT and 1353 patients with interferon-alpha. Among these patients, 384 and 141 showed complete response respectively (Figure-4). 
Figure 3 - Meta-analysis of Total Survival.

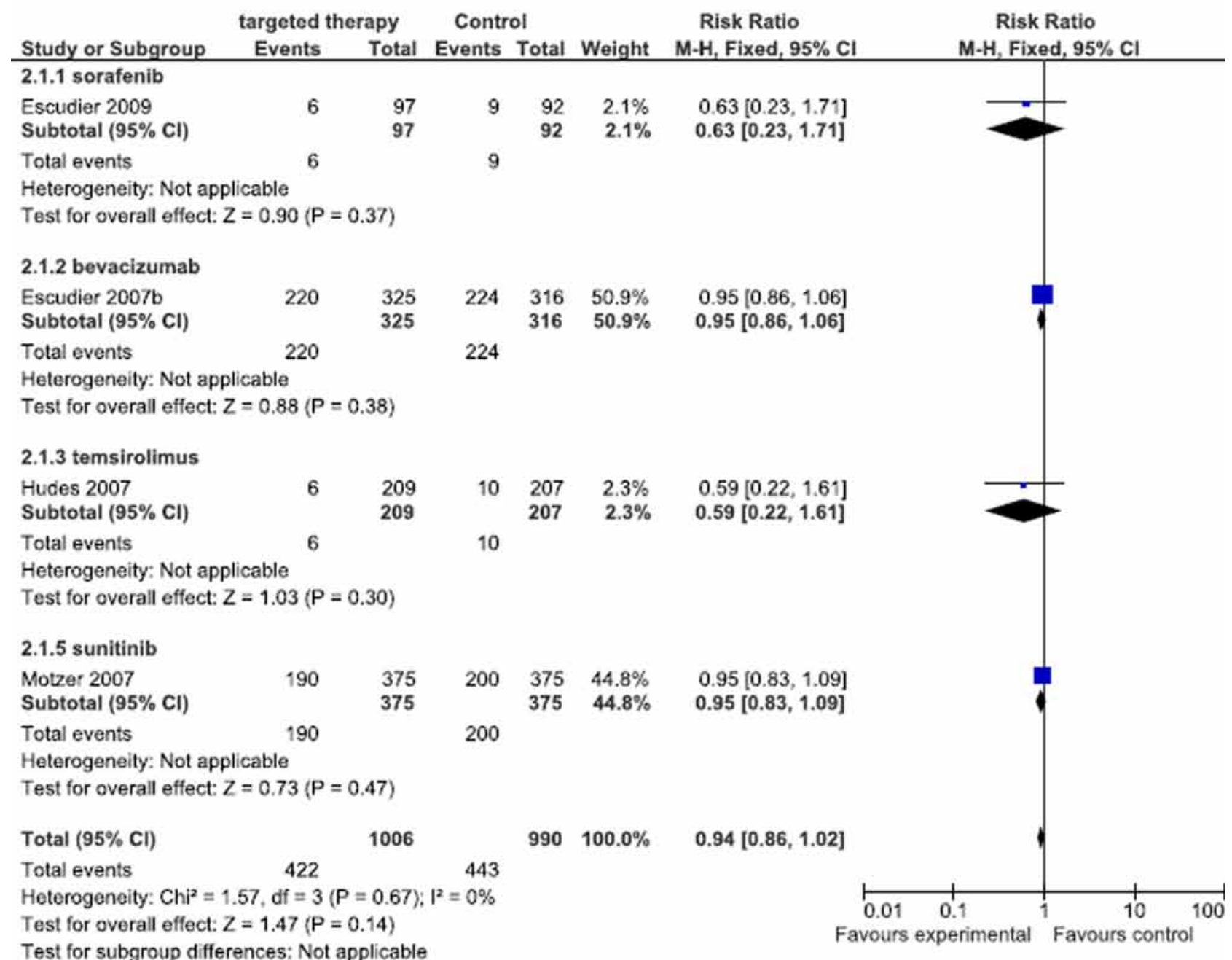

RRi obtained using meta-analysis of the studies was $2.68 \mathrm{CI}=2.25-3.20, \mathrm{I}^{2} 68 \%$ and $\mathrm{p}<$ 0.00001 . Best RR result was obtained with sunitinib (Motzer et al., 2007 (13)) with RRi of 3,83 and $\mathrm{CI}=2.86-5.12$. Following, according to favorable responses: bevacizumab, $\mathrm{RRi} 2.52 \mathrm{CI}=1.78-3.57$ (Escudier et al., 2007 (9)), bevacizumab, RRi 1.97 $\mathrm{CI}=1.43-2.71$ (Rini et al., 2010 (16)), temsirolimus, RRi 1.78 CI = 0.84-3.77 (Hudes, et al., 2007 (12)) and finally sorafenib, RRi $0.32 \mathrm{CI}=0.01-7.62$ (Escudier et al., 2009 (10)).

Heterogeneity $\left(\mathrm{I}^{2}\right)$

Due to the high level of $\mathrm{I}^{2}=94 \%$ at meta-analysis of FPS and of $\mathrm{I}^{2}=68 \%$ at objective RR, several analysis were made excluding each work of the respective meta-analysis. TS meta-analysis showed $\mathrm{I}^{2}=0 \%$, so the analysis of heterogeneity was unnecessary.

During FSP analysis the maximum value obtained for heterogeneity was observed when the study of Rini et al (2010 (16) was excluded: $\mathrm{I}^{2}=89 \%$, showing great heterogeneity among the studies. After excluding the study of Motzer et al., 2007 (13) during RR analysis heterogeneity value was $\mathrm{I}^{2}=0 \%$.

\section{Second line studies}

It was not possible to perform meta-analysis, since populations of both studies were quite different. One of the studies included patients 
Figure 4 - Meta-analysis of Response Rate.

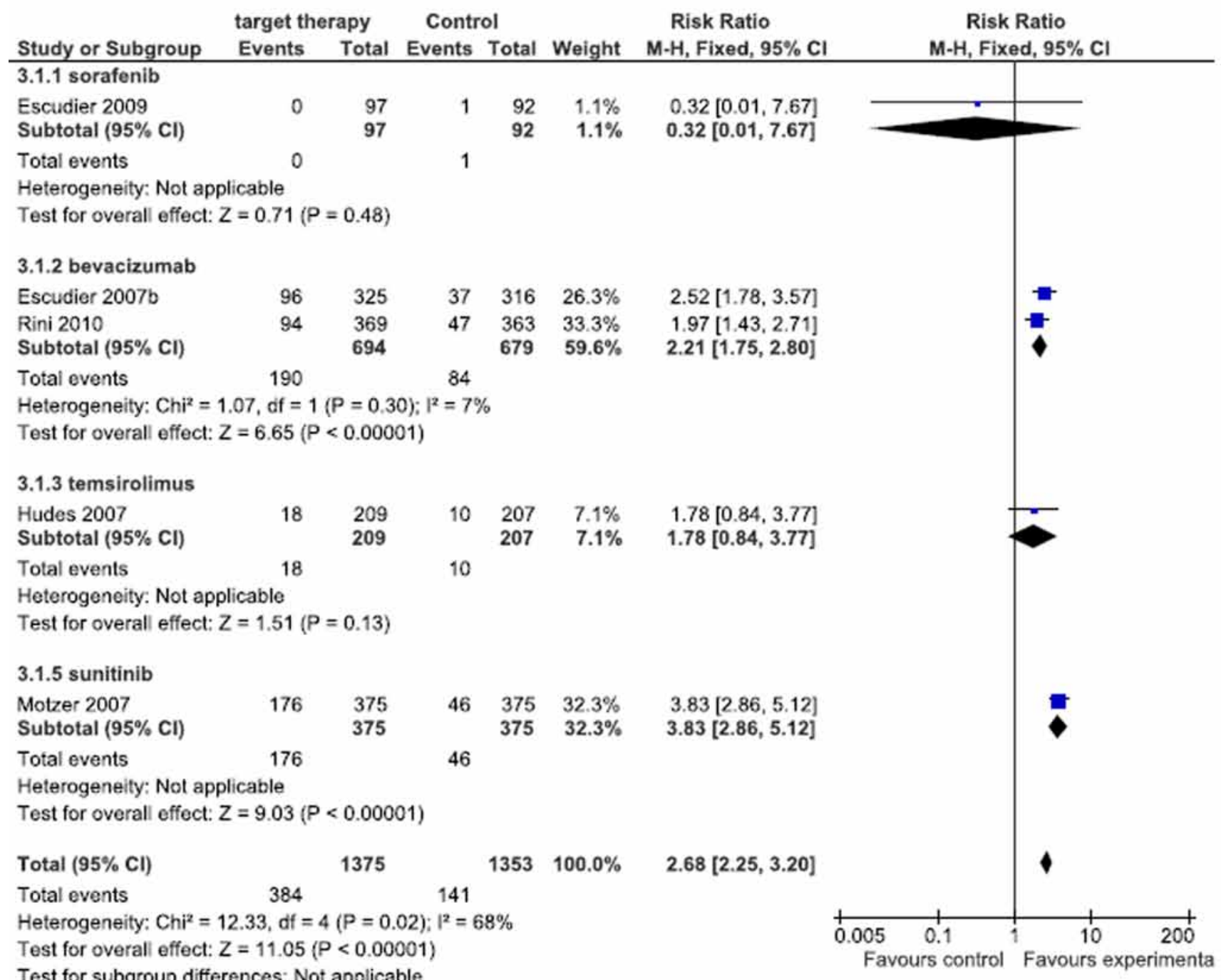

previously treated with systemic therapy and the other patients treated previously with sunitinib, sorafenib or both (Escudier et al., 2007 (18) and Motzer et al., 2008 (19), respectively).

\section{SURVIVAL CURVES}

FSP curves of first line treatments showed little improvement, in order of importance, with the use of sunitinib, bevacizumab and interferon- -alpha. TS curves were very similar and with no statistical differences (Figure-5).

In relation to first line treatments of high risk patients, FSP and TS curves showed a little better improvement with temsirolimus, compared to interferon-alpha (Figure-6).

TS curves of second line treatment were very similar and with no significant difference, while FSP curves showed some advantages, in order of importance, with the use of everolimus, 
Figure 5 - Free survival progression and total survival curves for first line treatment.

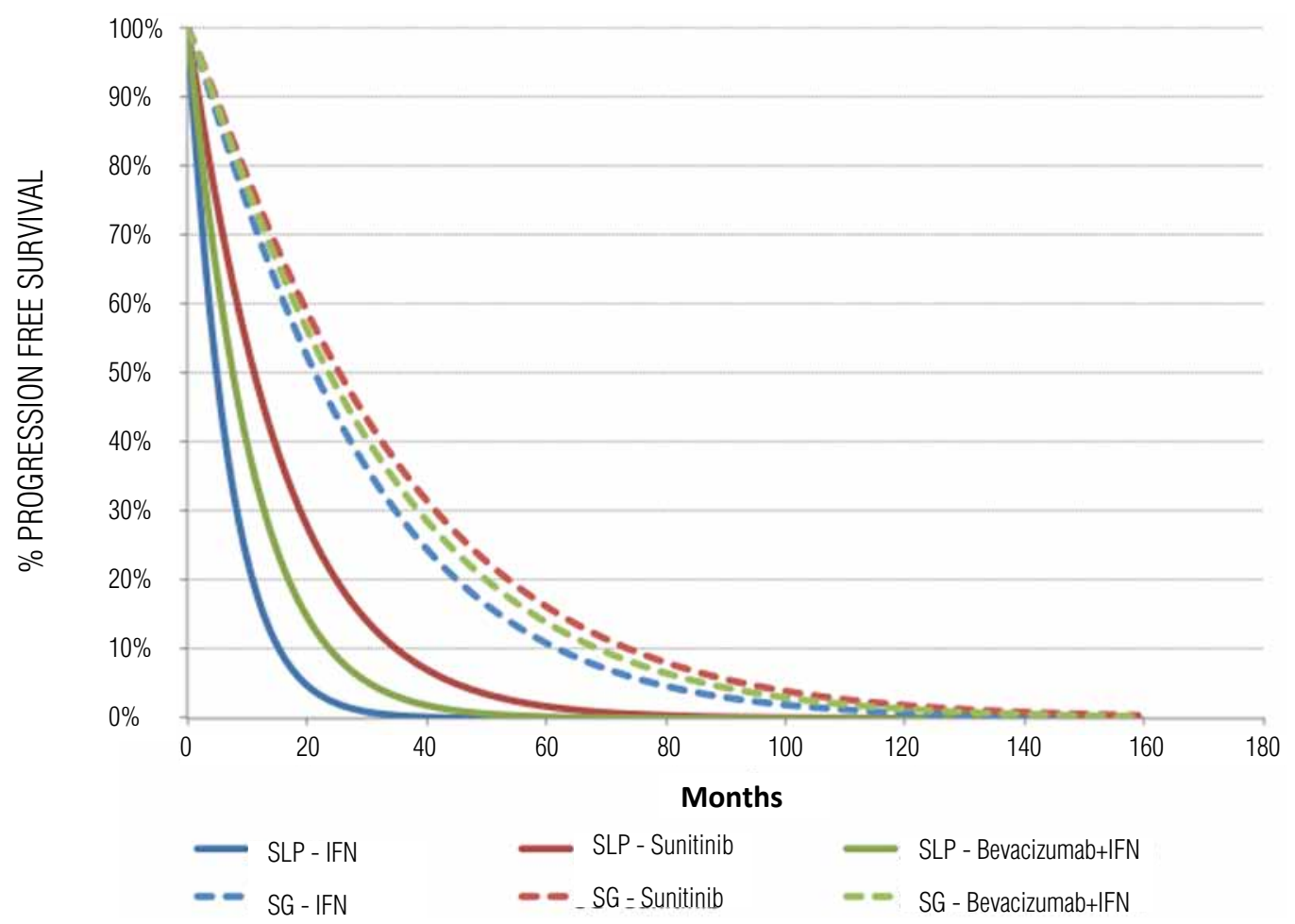

Figure 6 - Free survival progression and total survival curves for first line treatment of high risk patients.

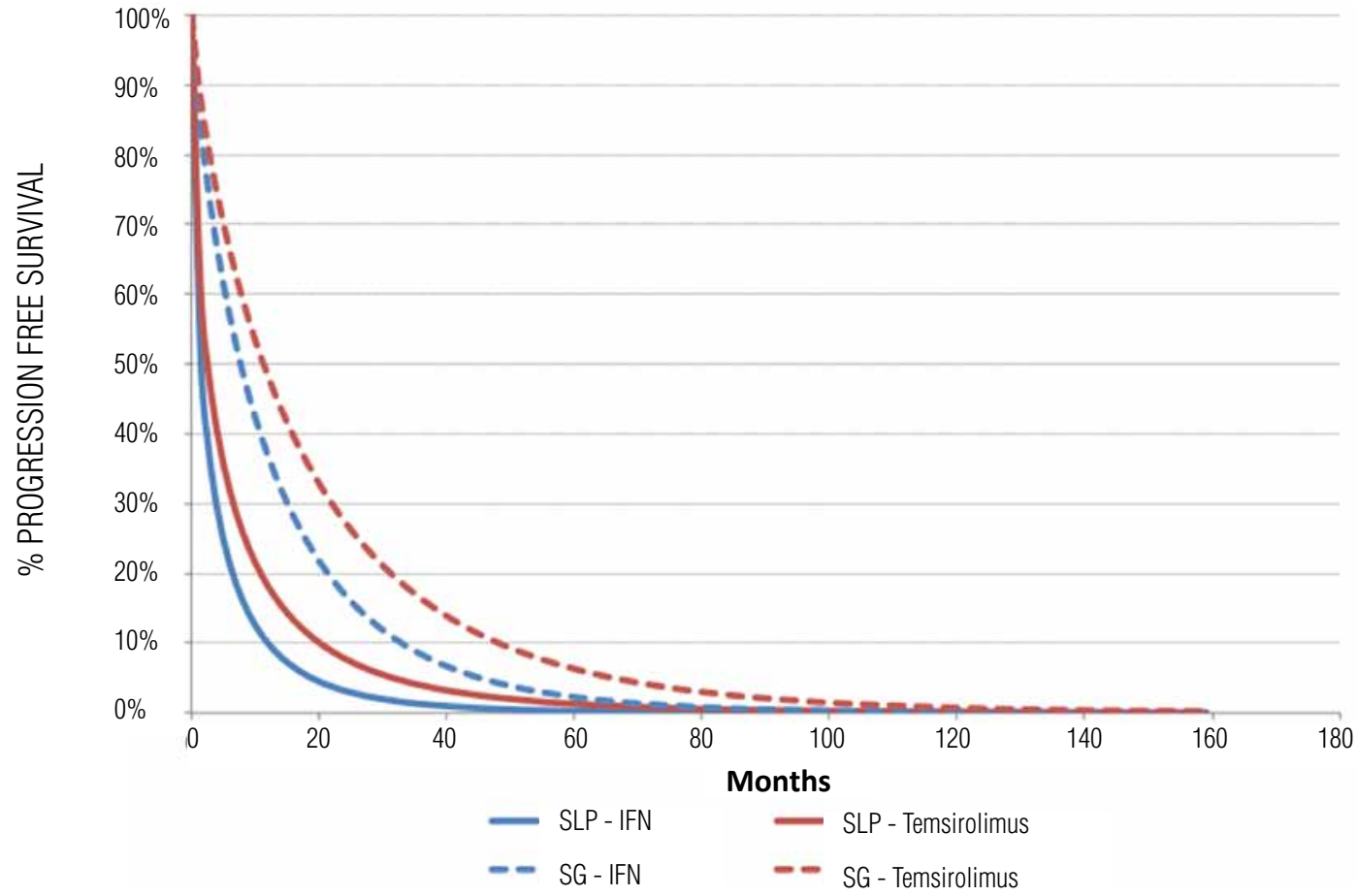


sorafenib and finally only palliative care (BSC) (Figure-7). As previously related, second line treatments were very heterogeneous and it was not possible to perform meta-analysis.

\section{DISCUSSION}

The lack of suitable studies that evaluate efficiency of target cell therapies (TCT) for advanced renal cell carcinoma (ARCC) was noted during systematic review and only a few were submitted to meta-analysis: seven first line treatments and two second line treatments.

It was also observed difficulty to collect data from the studies, since some presented not clear and non-objective results. Among the revised studies, there were several difficulties regarding interpretation of results, such as randomization, quantification of response rate, number of deaths during the study, that impaired TS calculus.
Many selected works were excluded since they were not prospective and with a control group, randomized and with the necessary information for analysis. Subgroup analysis studies were also excluded as well as those with duplicated populations.

At present, there are several available treatments with TCT, as well as with pazopanib $(21,22)$, axitinib (23) and tivozamib (24). However, only studies that used sorafenib, sunitinib, bevacizumab, temsirolimus and everolimus were included for comparision with interferon-alpha.

Meta-analysis of FSP showed RRi with a slight favoring for the treatment with TCT compared to control group treated with IFN- $\alpha$ (RRi 0,83 $\mathrm{CI}=0.78$ - 0.87). However, two aspects must be pointed out. First, better result of RRi sunitinib (RR $0.38 \mathrm{CI}=0.25-0.58$ (13)) compared to other drugs, showing better efficacy of this drug as first line treatment. Second, bevacizumab studies showed

Figure 7 - Free survival progression and total survival curves for second line treatment.

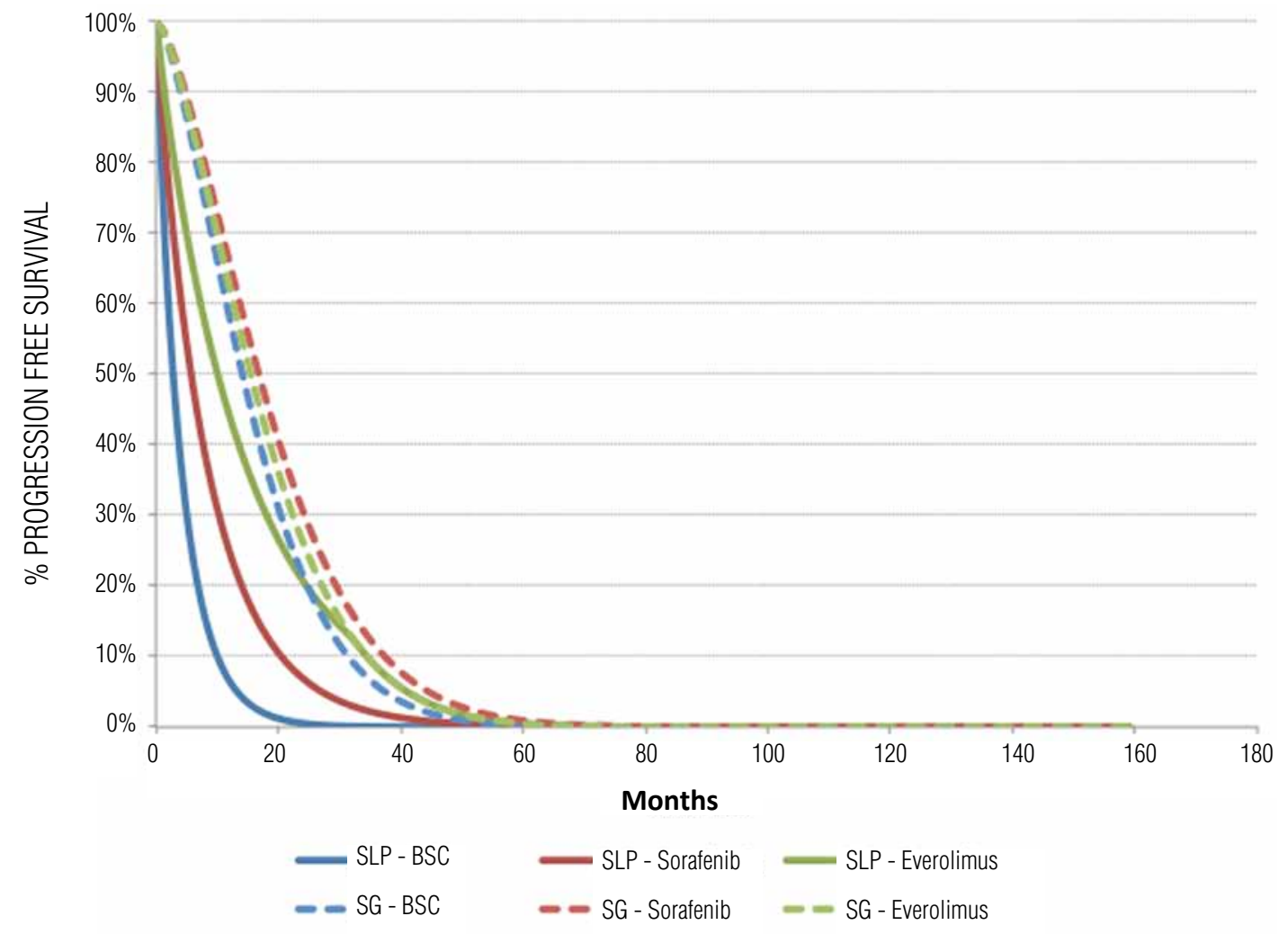


different and controvertial results (Escudier et al., 2007 (9) and Rini et al., 2010 (16)), with different Rris and CIs: RR $0.62 \mathrm{CI}=0.47-0.83$ and RR 0.97 $\mathrm{CI}=0.92-1.02$, respectively.

RRi values of TS of the sorafenib studies (Escudier et al., 2009 (11)), bevacizumab (Escudier et al., 2007 (9)), sunitinib (Motzer et al., 2007 (13)) and temsirolimus (Hudes et al., 2007 (12)) did not indicate significant differences of TS RRi of patients of control group, confirmed by the value of $\mathrm{I}^{2}=0$.

In relation to $\mathrm{RR}$ meta-analysis, treatment with sunitinib was superior (RR 3.83 and CI [2.86-5.12]), compared to other drugs. This difference was so bigger that, when the heterogeneous analysis was performed, the initial $\mathrm{I}^{2}$ was $68 \%$ and became $0 \%$ after the exclusion of that paper (Motzer et al., 2007 (13)).

All simulations of heterogeneity analysis of FSP showed high I2 (> 50\%) demonstrating that the five first line treatment studies are not homogeneous. The differences may be related to varied results of efficiency of the four drugs, population characteristics and methodologies. It was not possible to prove that the five studies presented homogeneously results of FSP. In the future, further studies are necessary with a bigger and more homogeneous population.

\section{CONCLUSIONS}

For first line treatment, sunitinib is the most efficient therapy regarding FSP; the studies did not show any improvement of TS and RR was low, but significant, using sunitinib and bevacizumab. Available studies could not conclude the use as second line therapies. Those results must be carefully analyzed due to the small number of available studies.

\section{CONFLICT OF INTEREST}

None declared.

\section{REFERENCES}

1. Fisher RI, Rosenberg SA, Fyfe G: Long-term survival update for high-dose recombinant interleukin-2 in patients with renal cell carcinoma. Cancer J Sci Am. 2000; 6(Suppl 1): S55-7.
2. McDermott DF, Regan MM, Clark JI, Flaherty LE, Weiss GR, Logan TF, et al.: Randomized phase III trial of high-dose interleukin-2 versus subcutaneous interleukin-2 and interferon in patients withmetastatic renal cell carcinoma. J Clin Oncol. 2005; 23: 133-41. Erratum in: J Clin Oncol. 2005; 23: 2877.

3. Motzer RJ, Murphy BA, Bacik J, Schwartz LH, Nanus DM, Mariani T, et al.: Phase III trial of interferon alfa-2a with or without 13-cis-retinoic acid for patients with advanced renal cell carcinoma. J Clin Oncol. 2000; 18: 2972-80.

4. Yang JC, Sherry RM, Steinberg SM, Topalian SL, Schwartzentruber DJ, Hwu P, et al.: Randomized study of high-dose and low-dose interleukin-2 in patients with metastatic renal cancer. J Clin Oncol. 2003; 21: 3127-32.

5. Higgins JPT, Green S. Cochrane Handbook for Systematic Reviews of Interventions Version 5.0.2 [updated September 2009]: The Cochrane Collaboration; 2008. Available at: www.cochrane-handbook.org

6. The Nordic Cochrane Centre. Review Manager (RevMan) [Computer program]. Version 5.0. Copenhagen: The Cochrane Collaboration; 2008. Available at: http://ims.cochrane.org/home

7. Higgins JP, Thompson SG, Deeks JJ, Altman DG: Measuring inconsistency in meta-analyses. BMJ. 2003; 327: 55760.

8. Cella D, Li JZ, Cappelleri JC, Bushmakin A, Charbonneau C, Kim ST, et al.: Quality of life in patients with metastatic renal cell carcinoma treated with sunitinib or interferon alfa: results from a phase III randomized trial. J Clin Oncol. 2008; 26: 3763-9.

9. Escudier B, Pluzanska A, Koralewski P, Ravaud A, Bracarda $S$, Szczylik $C$, et al.: Bevacizumab plus interferon alfa-2a for treatment of metastatic renal cell carcinoma: a randomised, double-blind phase III trial. Lancet. 2007; 370: 2103-11.

10. Escudier B, Szczylik C, Hutson TE, Demkow T, Staehler M, Rolland F, et al.: Randomized phase II trial of first-line treatment with sorafenib versus interferon Alfa-2a in patients with metastatic renal cell carcinoma. J Clin Oncol. 2009; 27: 1280-9. Erratum in: J Clin Oncol. 2009; 27: 2305.

11. Escudier B, Bellmunt J, Négrier S, Bajetta E, Melichar B, Bracarda $S$, et al.: Phase III trial of bevacizumab plus interferon alfa-2a in patients with metastatic renal cell carcinoma (AVOREN): final analysisof overall survival. J Clin Oncol. 2010; 28: 2144-50.

12. Hudes G, Carducci M, Tomczak P, Dutcher J, Figlin R, Kapoor A, et al.: Temsirolimus, interferon alfa, or both for advanced renal-cell carcinoma. N Engl J Med. 2007; 356: 2271-81.

13. Motzer RJ, Hutson TE, Tomczak P, Michaelson MD, Bukowski RM, Rixe 0, et al.: Sunitinib versus interferon alfa in metastatic renal-cell carcinoma. N Engl J Med. 2007; 356: 115-24. 
14. Motzer RJ, Hutson TE, Tomczak P, Michaelson MD, Bukowski RM, Oudard $\mathrm{S}$, et al.: Overall survival and updated results for sunitinib compared with interferon alfa in patients with metastatic renal cellcarcinoma. J Clin Oncol. 2009; 27: 3584-90.

15. Rini BI, Halabi S, Rosenberg JE, Stadler WM, Vaena DA, Ou SS, et al.: Bevacizumab plus interferon alfa compared with interferon alfa monotherapy in patients with metastatic renal cell carcinoma: CALGB 90206. J Clin Oncol. 2008; 26: 5422-8.

16. Rini BI, Halabi S, Rosenberg JE, Stadler WM, Vaena DA, Archer $L$, et al.: Phase III trial of bevacizumab plus interferon alfa versus interferon alfa monotherapy in patients with metastatic renal cellcarcinoma: final results of CALGB 90206. J Clin Oncol. 2010; 28: 2137-43.

17. Yang S, de Souza P, Alemao E, Purvis J: Quality of life in patients with advanced renal cell carcinoma treated with temsirolimus or interferon-alpha. Br J Cancer. 2010; 102: 1456-60.

18. Escudier B, Eisen T, Stadler WM, Szczylik C, Oudard S, Siebels $\mathrm{M}$, et al.: Sorafenib in advanced clear-cell renal-cell carcinoma. N Engl J Med. 2007; 356: 125-34. Erratum in: N Engl J Med. 2007; 357: 203.

19. Motzer RJ, Escudier B, Oudard S, Hutson TE, Porta C, Bracarda $\mathrm{S}$, et al.: Efficacy of everolimus in advanced renal cell carcinoma: a double-blind, randomised, placebo-controlled phase III trial. Lancet. 2008; 372: 449-56.
20. Bukowski R, Cella D, Gondek K, Escudier B; Sorafenib TARGETs Clinical Trial Group. Effects of sorafenib on symptoms and quality of life: results from a large randomized placebo-controlled study in renalcancer. Am J Clin Oncol. 2007; 30: 220-7.

21. Sternberg CN, Davis ID, Mardiak J, Szczylik C, Lee E, Wagstaff $\mathrm{J}$, et al.: Pazopanib in locally advanced or metastatic renal cell carcinoma: results of a randomized phase III trial. J Clin Oncol. 2010; 28: 1061-8.

22. Rexer H: First-line therapy of advanced or metastasized renal cell cancer: open randomized phase III sequence study to examine the effectiveness and tolerance of sorafenib followed by pazopanib versus pazopanib followed by sorafenib in the first-line treatment of patients with advanced or metastasized renal cell cancer (SWITCH-2 - AN 33/11)]. Urologe A. 2012; 51: 724-6.

23. Rini BI, Escudier B, Tomczak P, Kaprin A, Szczylik C, Hutson TE, et al.: Comparative effectiveness of axitinib versus sorafenib in advanced renal cell carcinoma (AXIS): a randomised phase 3 trial. Lancet. 2011; 378: 1931-9. Erratum in: Lancet. 2012; 380: 1818.

24. Nosov DA, Esteves B, Lipatov ON, Lyulko AA, Anischenko AA, Chacko RT, et al.: Antitumor activity and safety of tivozanib (AV-951) in a phase II randomized discontinuation trial in patients with renal cellcarcinoma. J Clin Oncol. 2012; 30: 1678-85.
Correspondence address:

Marcela Andrea Durán Haun Seneatore, MD

Rua Luverci Pereira de Souza, 210

Campinas, São Paulo, Brasil

Telephone: + 5519 3289-1838

E-mail: marceladuranduran@gmail.com 